\title{
Social Media and Rwandan Youth Acculturation in Higher Education:Case of Students at IPRC Musanze
}

\author{
Dieudonne Karekezi, Florence Mukadisi, Protais Niyonshima, Jean Pierre Nkundimana, Jean de Dieu Kabanda, \\ Crispine Hahirwuwizera, Beatrice Niyigena, and Erneste Nshimiyimana \\ Department of Languages and Entrepreneurship, IPRC Musanze/Rwanda Polytechnic, PO Box: 226 Musanze, \\ Rwanda
}

\begin{abstract}
This study aims at exploring how the use of social media affects youth acculturation in higher education settings. It reflects on forms of acculturation that youth in higher education experience through the exploitation of social network platforms. In light of that, the study sought to identify various social network sites used by students at higher education; investigate typology of acculturation faced by students at IPRC MUSANZE and investigate how social media affect higher education youth acculturation. Both qualitative and quantitative methods were used for data collection and analysis. A sample size of 248 students was used. The research findings declared that from the use of social media, youth at higher education acquire new cultures, change behaviours and adopt living styles through both integration and assimilation which finally lead to acculturation. To remedy those cultural, behavioural, living styles, and linguistic emergencies that arise from the use of social network platforms, an awareness should be created in regard to the effective and efficient use of social media and prefer good values to bad behavioural aspects.
\end{abstract}

Keywords: Youth, social media/social network sites, assimilation, integration, adaptation, acculturation.

DOI: $10.7176 / \mathrm{JCSD} / 66-05$

Publication date:August $31^{\text {st }} 2021$

\section{Introduction}

Education is progressively becoming the driving forces behind our new social and economic structures. Education does not happen in isolation but it is carried out through societal, environmental and human channels. Through education, the youth and future generations receive knowledge and traditions that help them enter into the totality of reality. Therefore, a main concern of society is primarily to teach the youth to promote the country's culture which embeds language, identity, values, and ethics to name few. In this line, the society shapes itself through its culture and related practices.

Within societies, ever since the come into contact of mankind, different aspects of societies have been changing. Such societal aspects include but not limited to culture which evolves and changes depending on different factors. The dynamics of culture change because of innovation, diffusion, enculturation, acculturation, assimilation, adaptation and directed change (Hatice, et al, 2020).

This study sheds light on how social media platforms affect students in higher education. In fact, besides discussing the process of acculturation, this study analyses typology and effects of social media to Rwandan higher education students. Also, it ends by proposing interventions to address forms of negative effects of acculturation from social media.

\section{Background to the study}

Going back to the history of Rwandan culture, the family served as the basic organizational unit in the society and it played a watchdog function to ensure that values were inculcated in the youngsters to prepare them for adulthood. The focus was to be put on patriotism, proper use of the language, social relations, dance and the defence of the nation. As an outcome young citizens could grow with an understanding and attachment to their culture. Rwanda (Ministry of Sports and culture, 2015).

Culture is defined as a set of distinctive spiritual, material, intellectual and emotional features of society or a social group, that encompasses, not only art and literature, but lifestyles, ways of living together, value systems, traditions and beliefs (UNESCO, 2001).

From empirical studies, culture plays a vital role in social growth and development of a country as well. Culture is a key to any country's identity. It is an overall mark of its politics, life, and practices. The literature by the Rwanda Ministry of Sports and Culture claims the culture of any country as an integral part of its overall political and socio-economic development framework. It is an embodiment of social cultural practices, integrated pattern of knowledge, belief system, behaviour, customs, language, ideas, taboos, rituals and festive events, codes manifested in the ways of life of a particular society and transmitted from one generation to another that make the structure of communities.

Such facts can be language use, physically pointed thins such as dressing codes, buildings, cooking, mutual conversations, and other practices to name few. These elements of the culture heritage need to be preserved for 
the future to keep the memory of the past, to offer a sense of identity and continuity, thus promoting respect for cultural diversity and human creativity. In fact, Rwanda finds its culture as a shelter of its language, values, traditions, rites and associated with social practices. (Rwanda Ministry of Sports and Culture, 2015)

Generally, culture has the power to transform entire societies, strengthen local communities and create a sense of identity for people of all ages. In this way, once it is well practiced, it affects the nation positively and negatively once diluted. In that vein, youth can act as a bridge between cultures and serve as key agents in sustaining the cultural legacy and identity as well as promoting intercultural understanding

The Rwandan national Anthem portrays that the shared culture binds its concerned people, the language unifies them. Besides "Umuco dusangiye uraturanga, Ururimi rwacu rukaduhuza". Besides, the eminent Rwandan scholar Rugamba pinpointed that the best culture that fed you never dare to deteriorate it. From the deeds of others select what you judge good and best on your side and leave chaffs away. "Umuco mwiza wakureze ntugatume udindira. Mu by'abandi jya utoranya ibyiza, ibifutamye ujugunye" (Rugamba, 1987)

However, to some extent people get acculturated due to different factors. In the light of this, acculturation consists in the process of cultural and psychological change that follows the contact of different cultures. Such concerns individual changes of attitudes or change of community's cultural identities and their social behaviours in relation to the groups in contact. Acculturation may also result from eventual adaptations of psychological features, including a person's wellbeing and social skills that are needed to function in their culturally-complex daily world (Ward, Bochner\&Furnham 2001Phinney, 2006; Berry, 2010,).

Other empirical studies claim acculturation as the crisis stage or culture shock that consists of frustration with living in an unfamiliar culture. It is then done in a gradual adjustment or as the full adjustment and adaptation. The same empirical studies view acculturation as culture shock or distress that everyone feels during intercultural adaptation that can influence their communication and behaviours (Sawyer, 2011; Kohls, 2001).

Social media are electronic medium of communication and used by all generations. With the advance of technology, social media platforms like Twitter, Instagram, WhatsApp, YouTube, Facebook, messenger, Skype and others are used in people's real-life communication for different purposes (Zahirah Zainal, Noor Hanim Rahmat,2020). In the $21^{\text {st }}$ era, the intense use of these social media within different societies impact on their people's acculturation

In fact, the fast development in technology lead to a wide adoption of different social networking sites (SNSs) or social media platforms, particularly among young people (Whiting \& Williams, 2013). This provides ease of access to SNSs so that people can interact or communicate with friends, family members, colleagues and members of interest groups on the globe. Scientific literature by Zaffar (2016) emphases that the rapid growth of science, technology has caused a great danger to our moral values whereby the young generation's dissatisfaction and revolt are the outcome of a decaying system of values. In that perspective, social media have become increasingly popular components of our everyday lives in today's globalizing society. Social media have thus provided a context where people across the world can communicate, exchange messages, share knowledge, and interact with each other regardless of the distance that separates them. Intercultural adaptation involves the process of promoting understanding through interaction to increase the level of fitness so that the demands of a new cultural environment can be met. Research shows that people tend to use new social media to become more integrated into the host culture during their adaptation and to maintain connections to their home countries (Sawyer, Rebecca, 2011).

In the advance of the $21^{\text {st }}$ era, social networks are frequently used by university students, as well as by the rest of the population worldwide to communicate, collect information, and share world knowledge and images. It is in this perspective this study seeks to explore how the use of social media by higher education students impact on the cultural change if not acculturation.

\section{Problem statement}

Despite the programs and policies that Rwanda has put into place to empower young generation to be good citizens, some of university students lose their social and cultural values due to adaptation, assimilation and acculturation, mostly learnt from global communities through Social Network Sites (SNSs). Upon their arrival in new host higher education institutions, students experience cultural stress at the level of academic, cultural, psychological and physical well-being behaviours (Selmer, 1999, 2001).

With the increase of globalization, complex economic, societal and cultural relations, students are adapting and assimilating to new cultures and hence lose their own identity. A number of nations, including Rwanda, are suffering from issues, challenges and negative effects linked to youth adaptation, assimilation, and acculturation. In light with this, empirical studies demonstrate that this era marks the general acculturation and young generation is at high risk. Singh (2017). Youth are excited to copying new fashions, strange and wrong practices out of the Rwandan culture. As a result, youth suffer from cultural and physical behaviour effects such as nudes' exposition, drug abuse, earlier sexual intercourses that lead to unwanted pregnancies (NCC,2012).

Such assimilation and adaptation to new cultural aspects from social media cause disruptive behaviours, 
academic poor performance, and attempt to adjust their own culture or total loss of self-identity. That is the case of the so-called stars that have a mindset of nudes' expositions and drug abuses pretending that it is their easiest way of celebrity (The New Times, 2018). These are, at a maximum level, the root cause of students' linguistic and cultural interferences. The deeper they get involved in all those exercises of cultural assimilation, adaptation and acculturation, the more they lose Rwandan cultural values. This study aims at exploring how social media impact on Rwandan youth acculturation in Higher Education Case of students at IPRC Musanze.

\section{Research objectives}

$>$ Identify various social network sites used by students at higher education

$>$ Investigate typology of students' acculturation at IPRC Musanze

$>$ Investigate how social media affect Higher education youth acculturation

\section{Review of literature}

This section concerns literatures, which establish how acculturation can occur from the use of social media by community members. Acculturation is a two-way direction transfer of cultures and norms due to direct contact between societies. (Zhao, 2007) It occurs when an individual or a community acquires new cultural features of another community because of direct or indirect contact and interaction.

Different researchers highlight that acculturation goes through assimilation; modification and changes in the areas of group identity. Additionally, different scientific scholars declared that acculturation goes through four pattern strategies. While a research by Ryder et al. (2000) and Berry (2010) proposed assimilation, integration, separation and marginalization as methods of acculturation, Mendoza and Martinez (1981) propose cultural resistance, shift incorporation and transmutation as typology of acculturation.

Many scientific literatures describe acculturation as a process that occurs when groups of different cultures brought together in contact, which consequently leads to changes in the cultural patterns. Although acculturation sounds a neutral term, it induces changes in one of the one community than in the other. Additional empirical studies find that acculturation falls into the context of a new group to a new settlement whereby that new group attempts to adjust to a new culture. In that light, in many of the empirical studies acculturation is viewed as undergoing changes in regard to cultural and linguistic markers, tradition, and food to name few of them.

Berry in Kyunghee Ma et al identifies acculturation as s stress or difficulties that arise when an individual or a community is struggling with new cultural adaptation and adjustment because of an imbalanced contact between two societies. In fact, acculturation refers to the acquisition and adaptation to the cultural values, attitudes and beliefs. (Kyunghee Ma et al, 2020; Xinying Xing et al, 2020; Harlow, Trina D., 2019; Berry\& Sabatier, 2011). Berry further asserts that acculturation is not a uniform process; it varies according to the range of strategies adopted by individuals immersed in cultural change and the socio-cultural contexts of the host culture (Berry’s, 2005).

\section{Social media and acculturation}

Rapid spread of information influenced by the globalisation has increased the social space, leading to borderless boundaries on cross cultural and linguistic dimensions of traditional societies. Moreover, empirical researches highlight that with the advance of digital information and web technologies have1 led to a wide adoption of different social media platforms and caused a great danger to culture and moral values among young people(Whiting \& Williams, 2013;Zaffar, 2016; Singh (2017).The easier access to Internet and increasing multiple demands facilitated the formation of online communities in Social Network Sites, which fostered the emergence of the online cultures with their corresponding behaviour and language practices (Mitra \& Evansluong, 2019). In addition, Chen and Zhang (2010) point out that the time and space is no longer an issue due to the convergence of new media and globalization that has made interaction much easier.

New social media has brought people from different cultures together in the "global village." With the widespread use of the Internet and social network (SNSs) that provide various sources of online information has become one of the most important communication tools for people from around the world (Murugesan, 2007; Williams et al., 2012). Using social media platforms and particularly online, is considered as an important part of many individuals' daily life and leads them to be exposed to new cultures (Eslami \& Yang, 2018). Briefly, the use of social media provides students with a room to cultural contact, which in turn, has made some people of different communities to be acculturated Raman and Harwood (2016). Cemalcilar et al. (2005) reported that using social media to communicate with the host country calls upon sociocultural adaptation to the host culture. Cultural traits, such as food, media, language, clothing, and daily practice of life or holiday celebrations are normally selected to detect the processes of acculturation (Schwartz et al., 2010). Cleveland et al. (2009) have highlighted the important traits in the acculturation process, such as food, media, interpersonal relationships, and language, participation in home and host cultures and self-identification. Media use serves as a primary driver by which immigrants become acculturated to a new social environment (Wilkin, Katz \& Ball-Rokeach, 2009). 


\section{Motives behind individuals or communities' acculturation}

Imitation and assimilation are some of the driven factors of individuals' acculturation. Young people tend to imitate others in their doings. They are excited to copying new fashions, strange and wrong practices out of home culture. Those are like among others, nudes' exposition in social media or artistic songs performance, irreverence from imitations which causes bad services delivery, idleness. These are besides at maximum level the root cause of copying foreign lifestyles, sinking in both cultural and linguistic interferences to name few. The deeper they get involved in all those exercises, the more they lose moral-cultural values and empowerment gets weakened. (NCC, 2012).

In the same perspective, self-identification is another strategy of youth acculturation. The youth attempt to balance two contrasting cultures or adjust to the host culture will result in changing one's cultural identity (Young, 2009). Furthermore, youth self-perception culturally and linguistically, leads them to behaving as foreign people outside of their primary support group. Additionally, lack of academic language proficiency, language regionalization, language variation and general academic challenges in higher education are other acculturation stresses that youth face; (Kyunghee Ma et al, 2020).

\section{Cultural and Linguistic effects from using social media}

Internet emergence and the rise of social networking have transformed communication. Consequently, social media has had far-reaching impacts on the way people communicate. Researches by Rosen et al and Sawyer stress that with social media, cultural differences influence communication, behaviour, and values. In this vein, with social network sites young people try to identify with different cultures, based on both national identity and gender, differences in individualistic and collectivistic cultures are apparent in users' communication and behavioural styles. The language presenting in the social media is changing the way students at Higher education use the language and how they behave culturally. That nature of communication through networking platforms is changing the way students write and speak the language. Thanks to electronic based communication platforms many changes are being operated in terms of using languages in different communities. As various scientific studies have observed social media affect the language used by the youth and students at tertiary education are part of them (Rosen et. al, 2010; Sawyer, Rebecca, 2011).

According to literatures by Dalzell \& Victor; Horobin and Sherly Marliasari, inappropriate use of the language; appropriation of the vocabulary; the use of acronyms and symbolic language; neologism and language evolvement in the real world; community member anti-socialism are direct or indirect effects of social media on community members' acculturation.

The same scientific literature by Dalzell \& Victor 2017 asserted that social media have weakened the use of appropriate use languages. Many of students at higher education use language jargons and/or slangs obtained from social media. Those students use that improper language without distinguishing where, whom and how to use that language. Thus, students at higher education, referring to social media, they abuse the language; they do not recognise the language registers and deserved addressees.

It is in that line those slangs are whether used intentionally or not while communicating with parents, teachers, lecturers, or others. Consequently, those improper uses of language by social media that students at higher education copy from social media affect their cultures. (Dalzell \& Victor, 2017; Horobin2018; Sherly Marliasari,2017)

Besides, other significant effects of social media on the way young people speak and write the language is the appropriation of vocabulary. They tend to create new slangs to express their feelings and understanding among themselves. Those slangs mostly mislead many people to use the language with incorrect spelling either syntactically or semantically.

According to the Information Resources Management Association (2016), there is the likelihood of a general weakening in proper language skills because most conversations on social media are full of abbreviations and misspelled words. Scholars in discourse linguistics and social media also added that abbreviations and improper language use may be comprehensible among teens and young people but older people sometimes have problems understanding the modern informal language. However, for many people, the use of informal language as influenced by social media seems to have made English simpler, but the ability to communicate deep thoughts is perhaps eroded. (Hoffmann and Bublitz, 2017; Zappavigna, 2012).

The same scholars Hoffmann and Bublitz further declare that the intense use of acronyms and symbolic language are also weakening and misleading cultural and linguistic features that lead to acculturation by alienation and laziness in improving language skills. Illustration are OMG (Oh my God), TTYL (talk to you later) to name few of them. In the same line, the same empirical studies have translated the use of symbolic language to representing facial emoticons or expression like smile, sadness by combinations of keyboard characters to convey what the user's feeling without having to write it in lazy form of writing.

Researches by Horobin (2018) and (Zappavigna 2012), identified neologism and language evolvement in the real world or the creation of new words ever heard before as notable impact of social media on the way 
people use the language. New terms such as "selfie," "memes," introduced in social media are now part of daily conversations both verbal and written. Some the created words have even been incorporated in dictionaries or in corpus lexicon of some linguistic fields on the social webs.

To round up the point of literature review, the advance of social media has led to shift within communication. With online communication, participants do not always get a very good sense of other people in the group. (Lievrouw; 2011: 222; Kear (2010: 31)

\section{Methodology}

This section presents various methods and procedures that were used in data collection, analysis and interpretation. A research by Karissa et al (2019) and the table of Krejcie \& Morgan (1970). stipulate that 20\% may represent a total population. Thus, a sample of 248 students of IPRC Musanze was used as sample size. Besides, IPRC Musanze, one college of Rwanda Polytechnic was used as a sample that represents other Higher Learning Institutions (HLIs) in Rwanda sharing the same characteristics of being a hub of young generation. The case study enabled researchers to understand the challenges and effects faced by young generation vis-à-vis social media and acculturation. Bryman (2004) explains that a case study involves the detailed and intensive analysis of a single case or sometimes extended to include the study of just two or more cases for comparative purposes.

For the effectiveness of findings, within this study, researchers used both qualitative and quantitative approaches. Patton (2002) points out that both quantitative and qualitative data can be collected in the same study as both methods involve differing strengths and weaknesses; they constitute alternative but not mutually exclusive strategies for research.

The choice of data collection techniques was led by the objectives of this study. Thus, the researchers used semi-structured interviews, questionnaire, observation and documentary review. The latter was applied by considering the fact that there is no single instrument that is self-sufficient in data collection.

\section{Findings and discussions}

This section of the research presents the findings that were led by research questions as presented below.

Table 1: Range of respondents' age

\begin{tabular}{|l|l|l|}
\hline Number of respondents & $16-30$ & $31-40$ \\
\hline 248 & 248 & 0 \\
\hline $100 \%$ & $100 \%$ & $0 \%$ \\
\hline
\end{tabular}

$100 \%$ of the respondents are in the age range of 16-30. This indicates that all respondents fall in youth category according to Rwanda Constitution.

Table 2: Respondents' gender identity

\begin{tabular}{|l|l|l|}
\hline Number of respondents & Male & Female \\
\hline 248 & 174 & 74 \\
\hline $100 \%$ & $70 \%$ & $30 \%$ \\
\hline
\end{tabular}

$70 \%$ of the respondents represent male whereas $30 \%$ represent female. This indicates that IPRC Musanze, a TVET school is mostly enrolled by male students than female.

Table 3: Respondents' residence

\begin{tabular}{|l|l|l|}
\hline Number of respondents & Urban & Rural \\
\hline 248 & 150 & 98 \\
\hline $100 \%$ & $60 \%$ & $40 \%$ \\
\hline
\end{tabular}

$60 \%$ of the respondents live in urban area while $40 \%$ are from rural areas. This implies that people from urban areas are familiar with the use of Social Media platforms compared to those from rural areas.

Social Media platforms mostly used by students at higher education

The research findings showed that the following social media platform are mostly used by students at higher education in Rwanda: WhatsApp, Facebook, YouTube, Twitter, LinkedIn, WeChat, and Telegram.

Table 4: Reasons of youth at higher education for using social media

\begin{tabular}{|l|l|l|l|l|l|}
\hline $\begin{array}{l}\text { Number of } \\
\text { respondents }\end{array}$ & $\begin{array}{l}\text { Learning } \\
\text { new skills }\end{array}$ & $\begin{array}{l}\text { Celebrity/ build } \\
\text { reputation }\end{array}$ & $\begin{array}{l}\text { Making } \\
\text { money }\end{array}$ & $\begin{array}{l}\text { Relaxing } \\
\text { /chatting with } \\
\text { friends }\end{array}$ & $\begin{array}{l}\text { Networking/meeting new } \\
\text { friends }\end{array}$ \\
\hline $\mathbf{2 4 8}$ & 57 & 19 & 15 & 92 & 65 \\
\hline $100 \%$ & $23 \%$ & $8 \%$ & $6 \%$ & $37 \%$ & $26 \%$ \\
\hline
\end{tabular}

$37 \%$ of respondents use Social Media platforms for relaxing and chatting with friends. $26 \%$ of respondents use social media platforms for networking/meeting new friends. $23 \%$ represents respondents who use social media platforms in learning new skills. $8 \%$ represents respondents who use social media platforms to build their 
reputation. $6 \%$ represents respondents who use social media platforms as a source of income.

The figures in the table 5 indicate that students at higher education use social media platforms to interact with people from different cultures which influence their personalities and cultural identity.

\section{Figure 1. Motivates to use social media platforms}

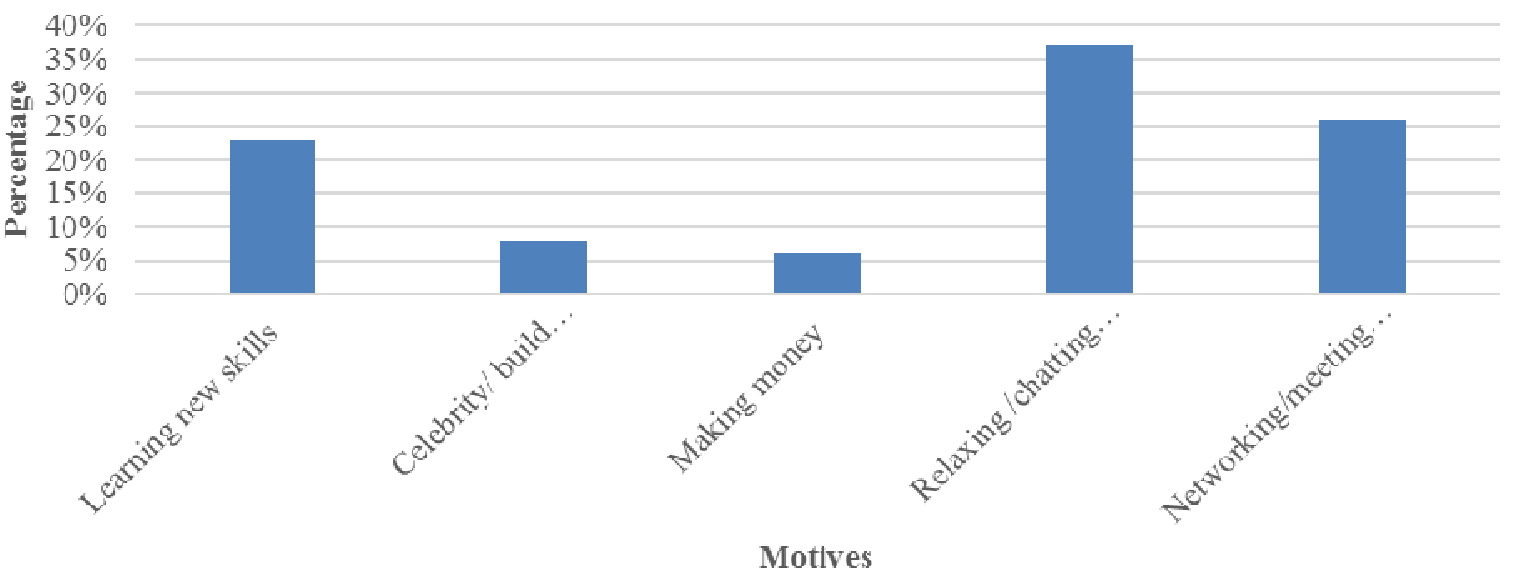

Figure 1 indicates that students at higher education use social media platforms to interact with people from different cultures which influence their personal cultural identity.

Table 5: Frequency of social media use

\begin{tabular}{|l|l|l|l|l|}
\hline Number of respondents & Hourly & Daily & Weekly & Monthly \\
\hline 248 & 80 & 121 & 38 & 9 \\
\hline $100 \%$ & $32 \%$ & $49 \%$ & $15 \%$ & $4 \%$ \\
\hline
\end{tabular}

$49 \%$ represents respondents who use social media platforms on daily basis. $32 \%$ of respondents use social media platforms hourly. $15 \%$ represents respondents who use social media weekly. $4 \%$ represents respondents who use social media platforms.

\section{Figure 2. Frequency of social media use}

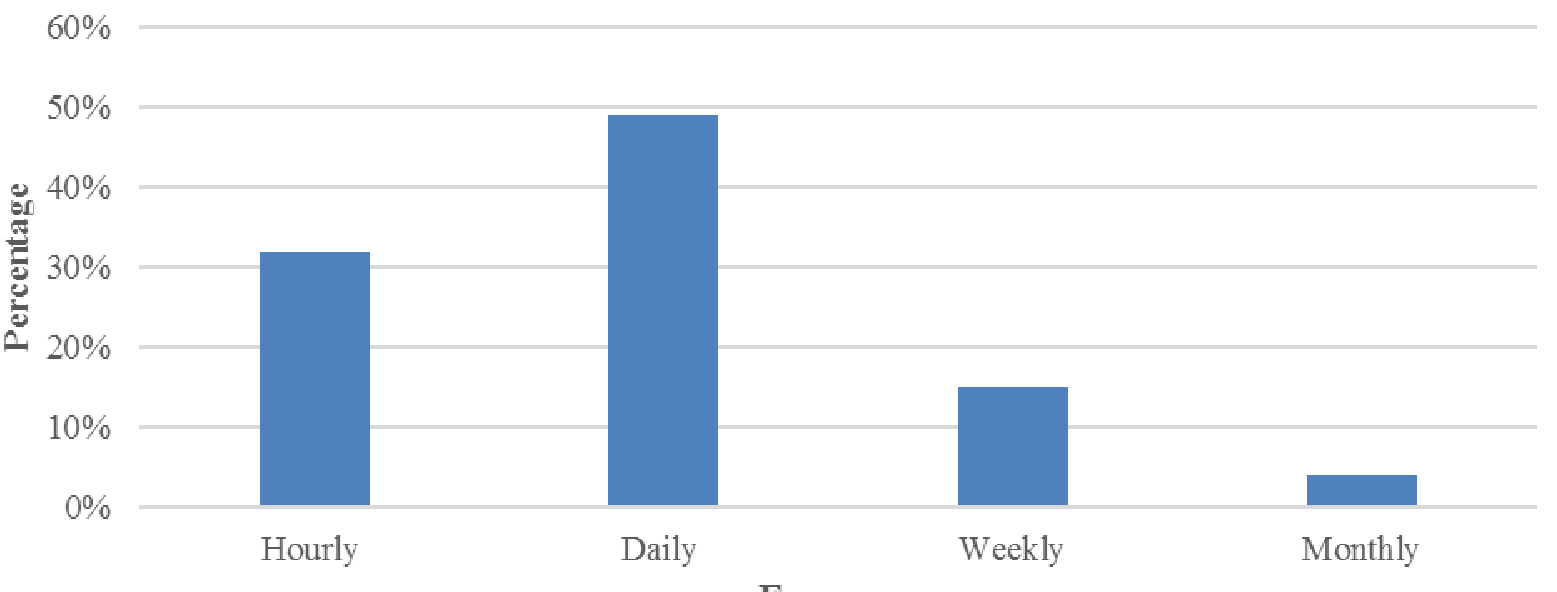

Frequency

Figure 2 shows that social media is part of students' life as a high percentage proves that they use them daily.

Table 6: Effects Social Network Sites on the culture of Rwandan

\begin{tabular}{|l|l|l|l|l|}
\hline Number of respondents & Negative & Positive & Both & None \\
\hline $\mathbf{2 4 8}$ & 106 & 58 & 84 & 0 \\
\hline $100 \%$ & $43 \%$ & $23 \%$ & $34 \%$ & $0 \%$ \\
\hline
\end{tabular}

$43 \%$ represents respondents who agree that Social Network Sites affect Rwandan culture negatively. $34 \%$ represents respondents who agree that Social Network Sites have both negative and positive effects on Rwandan culture. 23\% represents respondents who agree that Social Network Sites have positive effects on Rwandan 
culture. Data presented in table 7 indicate that the Social Network Sites have negative effects on the culture of Rwandan as represent by youth at Higher Education level.

Figure 3. Effects Social Network Sites on the culture of Rwandan youth especially at Higher Education level

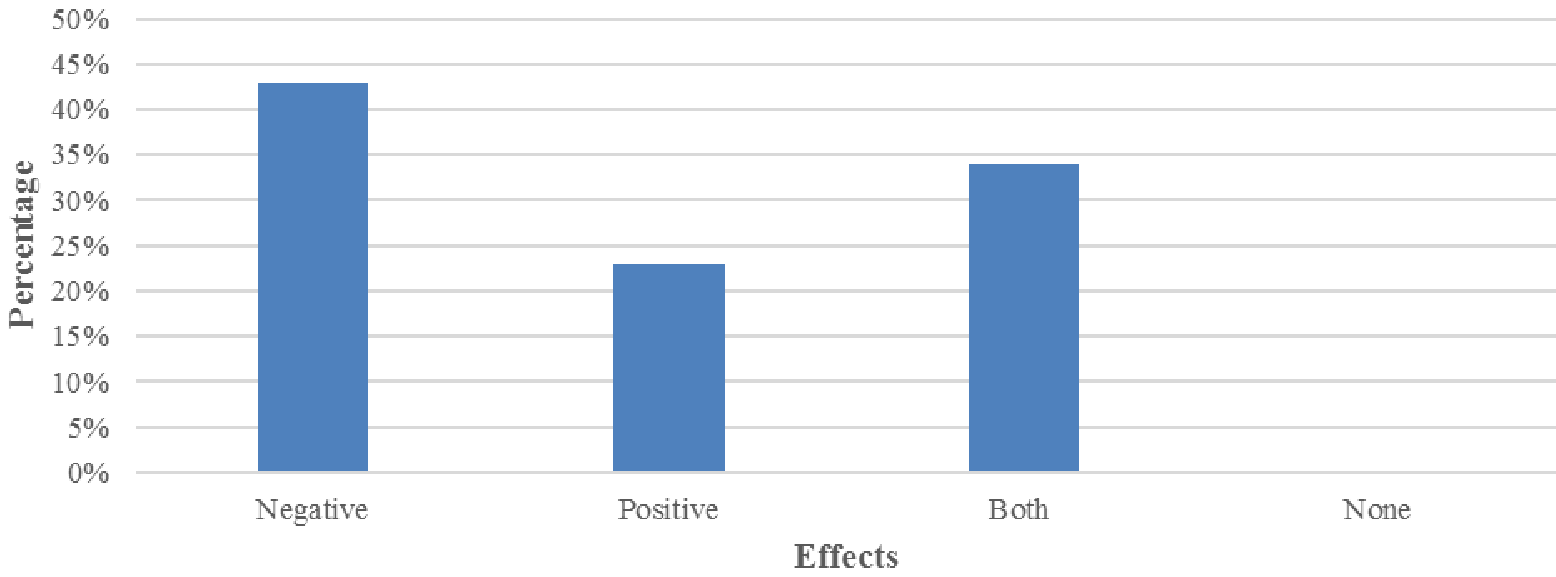

Data presented in Figure 3 indicate that the Social Network Sites have negative effects on the culture of Rwandan youth especially at Higher Education level.

Table 7: Forms of acculturation experienced by students at IPRC Musanze

\begin{tabular}{|l|l|l|l|l|}
\hline Number of respondents & Separation & Integration & Assimilation & Marginalization \\
\hline 248 & 36 & 109 & 103 & 0 \\
\hline $100 \%$ & $14 \%$ & $44 \%$ & $42 \%$ & $0 \%$ \\
\hline
\end{tabular}

From the data in the table 8 , the findings revealed that $44 \%$ of respondents testify that Social Media platforms influence youth at Higher education to practice culture integration and the latter is the most experienced type of acculturation. 42\% represents respondents who agree that assimilation is another form among the types of acculturation acquired by youth from Social Media platforms. 14\% represents respondents who agree that separation is one of the types of acculturation from Social Media platforms. This shows that the use of social media influences a big number of youth at higher education to accommodate foreign cultures along with the Rwandan culture.

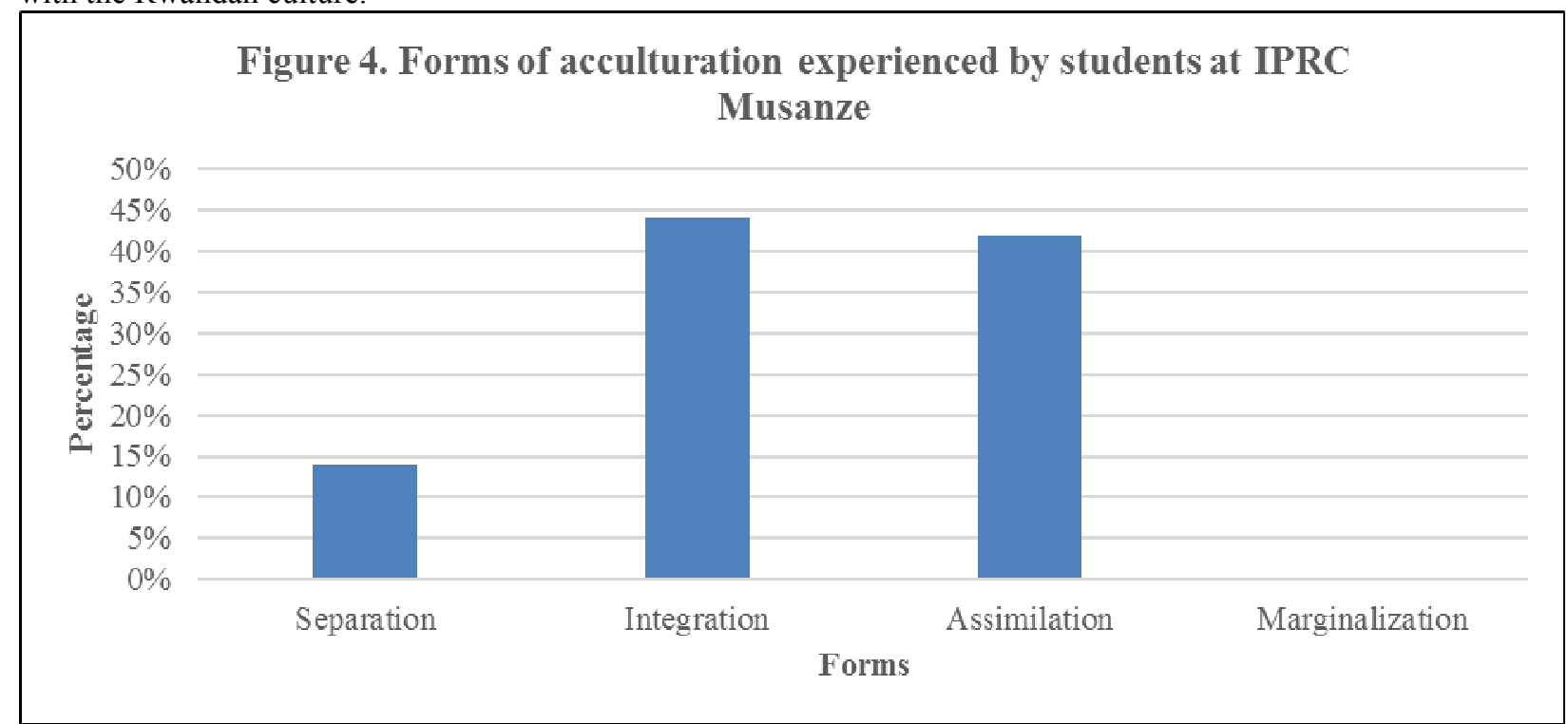

Figure 4 shows that a big number of respondents prefer to accommodate foreign cultures along with the Rwandan culture.

Table 8: Linguistic influence of Social Network Sites on Rwandan youth at Higher Education

\begin{tabular}{|l|l|l|l|}
\hline Number of respondents & Dilute Kinyarwanda language & Kinyarwanda language evolvement & None \\
\hline 248 & 135 & 81 & 32 \\
\hline $100 \%$ & $54 \%$ & $33 \%$ & $13 \%$ \\
\hline
\end{tabular}


$54 \%$ represents respondents who say that Social Network Sites contribute to the dilution of Kinyarwanda language. 33\% represents respondents who affirm that Social Network Sites contribute to the evolvement of Kinyarwanda language. 13\% represents respondents who state that Social Network Sites have no contribution to Kinyarwanda language.

This indicates that Social Network Sites have both negative and positive impacts. The findings revealed that though social media greatly weaken Kinyarwanda language by introducing other languages' patterns in it; Social Network Sites also contribute to the language evolvement by creating new language structures.

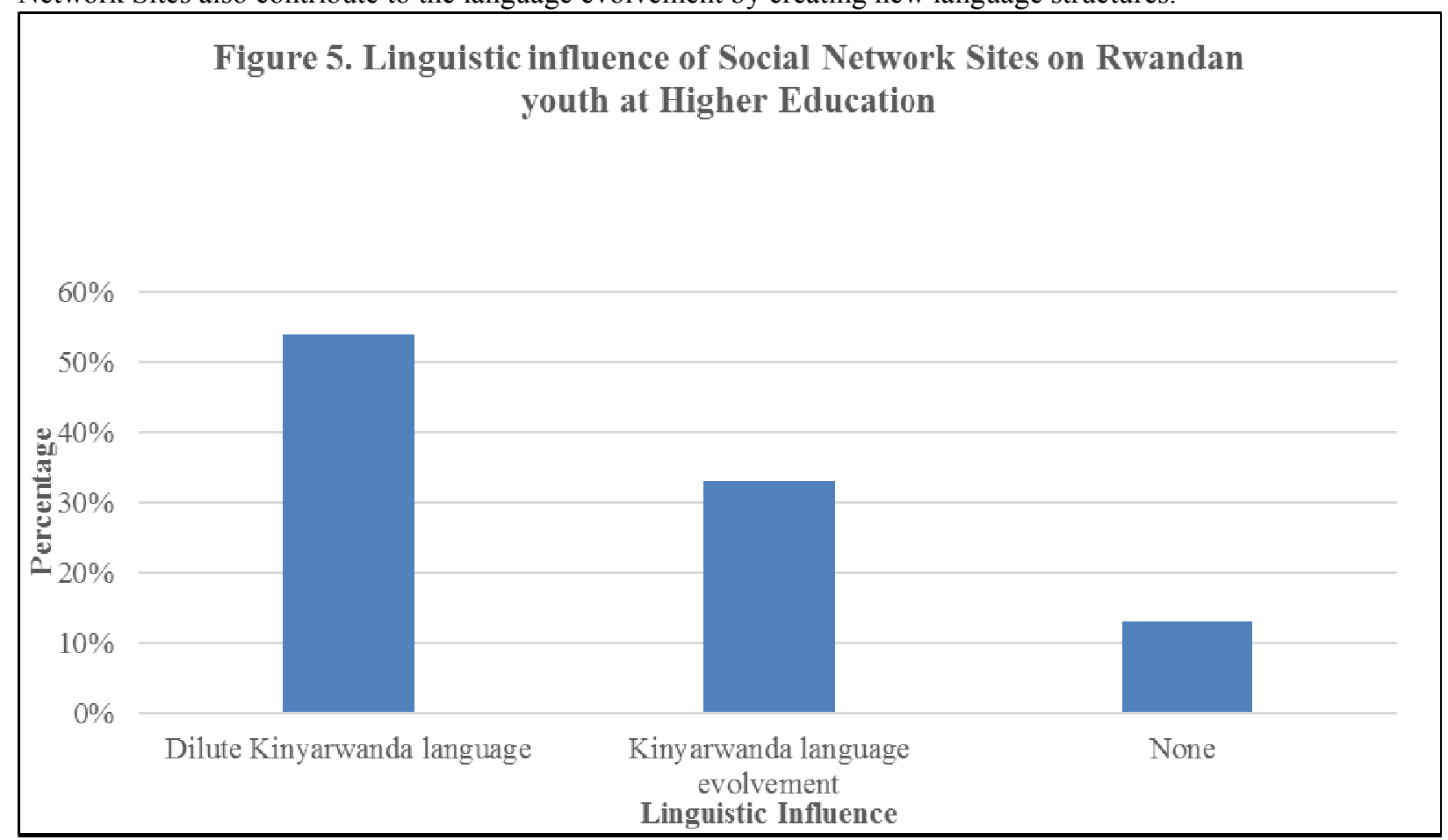

Figure 5 indicates that Social Network Sites have a great impact to the dilution of Kinyarwanda language by introducing other languages' patterns in it.

Table 9: Social media influence on youth living style (food, clothing, etc.)

\begin{tabular}{|l|l|l|}
\hline Number of respondents & Yes & No \\
\hline 248 & 178 & 70 \\
\hline $100 \%$ & $72 \%$ & $28 \%$ \\
\hline
\end{tabular}

$72 \%$ represents respondents who affirm that Social Media platforms influence their living styles. 28\% represents respondents who state that Social Media platforms have no influence on their living styles.

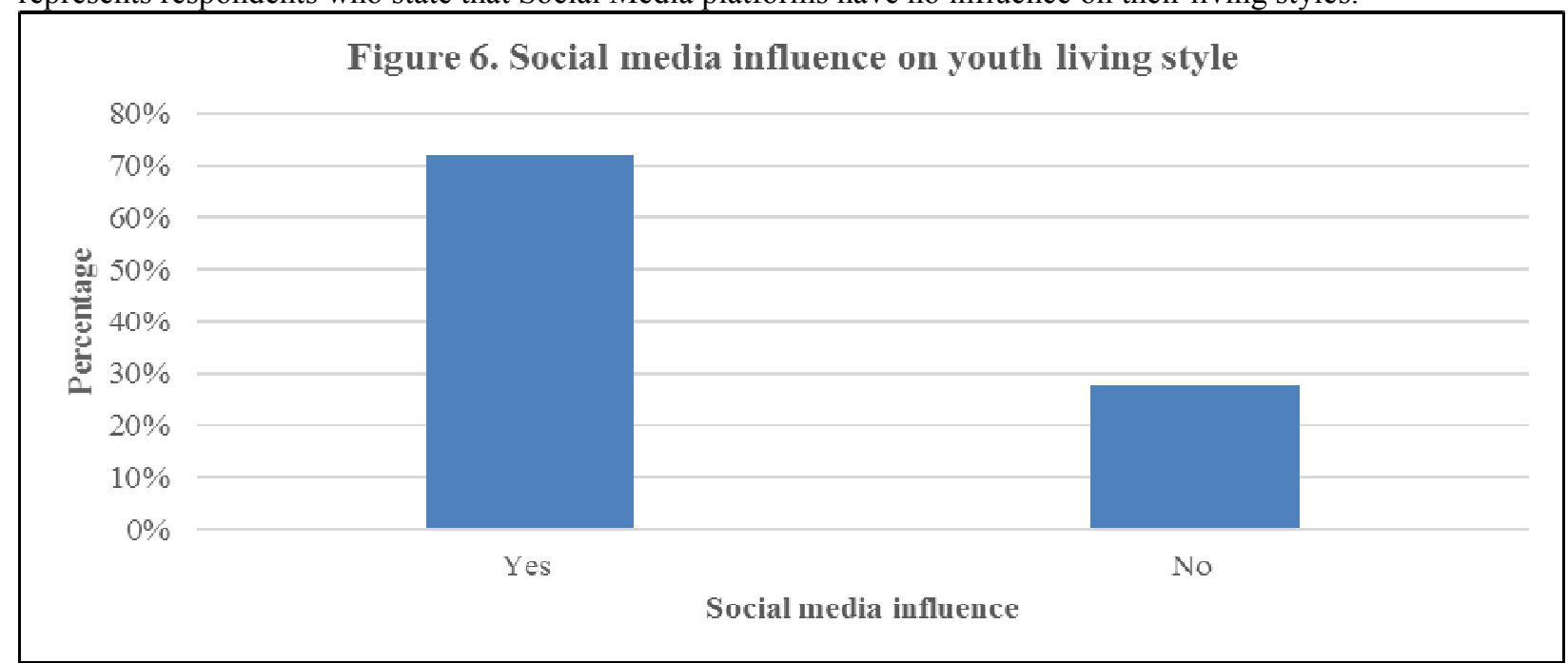

From Figure 6, it is observed that Social Media platforms influence the living styles of students at higher education in Rwanda in one way or another. 
Table 10: Influence of Social Network Sites on people's behaviours

\begin{tabular}{|l|l|l|l|l|l|}
\hline Number of respondents & Strongly agree & Agree & Strongly disagree & Disagree & Neither agree nor disagree \\
\hline 248 & 124 & 94 & 21 & 9 & 0 \\
\hline $100 \%$ & $50 \%$ & $38 \%$ & $8 \%$ & $4 \%$ & $0 \%$ \\
\hline
\end{tabular}

$50 \%$ of the total respondents strongly affirms Social Network Sites influence people's behaviours. $38 \%$ represents respondents who agree that Social Network Sites influence people's behaviours. $8 \%$ represents respondents who strongly disagree on Social Network Sites influence on people's behaviours. $4 \%$ represents respondents who disagree that Social Network Sites influence people's behaviours.

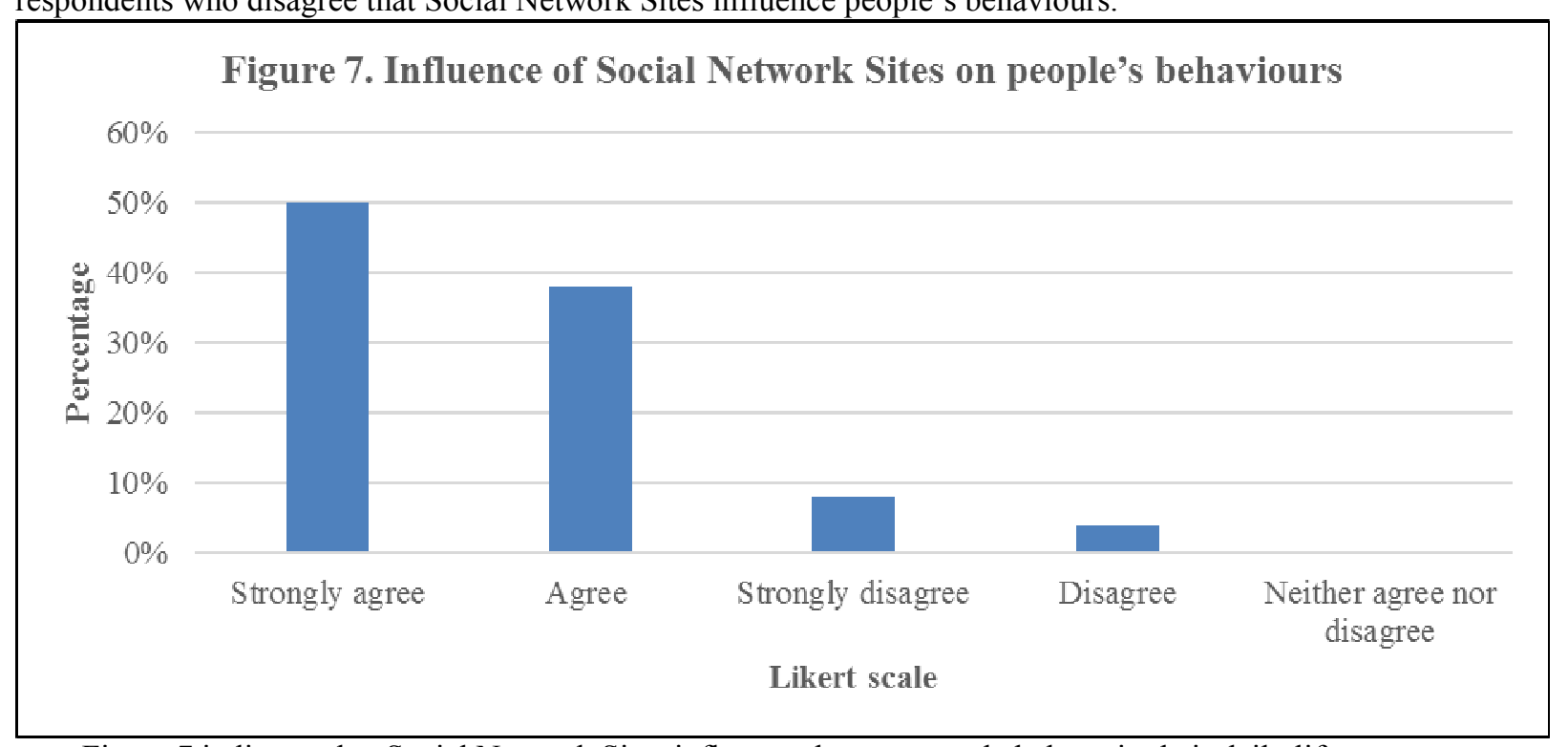

Figure 7 indicates that Social Network Sites influence the way people behave in their daily life.

\section{Conclusion}

The widespread use of the internet and social platforms has provided various sources of online information and become one of the most important communication tools for people worldwide. Rwandan young generation especially those in higher learning education are not left behind. The intensive use of social media has contributed to the youth's integration and assimilation of cultures which in turn lead to acculturation. In the same vein, the study aimed at exploring how the use of social media affects students' acculturation in higher education settings. It reflects on forms of acculturation that youth in higher education experience through the exploitation of social network platforms. Recommendations as strong interventions are suggested to address forms of negative effects of acculturation from social media.

Both qualitative and quantitative methods were used to collect, present and analyse data. The findings have proven that Social Network platforms have effects on youth at higher education. Moreover, findings revealed that from using social media, youth at higher education acquire various cultures by integration, adaptation and assimilation which lead to acculturation. The acculturation of Rwandan youth at higher education level was reflected in losing Rwandan cultural identity and efficient use of Kinyarwanda language command. It is worth saying that due to accommodating foreign cultures, integrating foreign language structures, and creating new language structures influence the Rwandan youth's living styles, behaviours and language use in their daily life. From the findings of the research, youth and all readers of this paper it is recommended to well utilise social media, preserve national cultural identity and values. Learning from others is good but it is wise to choose the best practices from other cultures and not grasping everything presented by social media platforms. As stated by Rugamba (1987), it is wise to keep firm practices in line with a country values and in accordance with the culture of the society someone lives in.

\section{References}

Berry, J. W., Phinney, J. S., Sam, D. L., \& Vedder, P. (Eds.). (2006). Immigrant youth in cultural transition: Acculturation, identity, and adaptation across national contexts. Lawrence Erlbaum Associates Publishers.

Bryman, A. (2004) Social research methods. 2nd Edition, Oxford University Press, New York, 592.

Cemalcilar, Z. Falbo, T., \& Stapleton, L.M. (2005). Cyber communication: A new opportunity for international students' adaptation? International Journal of Intercultural Relations, 29(1): 91-110.

Cyprien Rugamba (1987) Ngucireumugani, INRS.

Dalzell \& Victor (2017), Social Media Impacts on The English 
Languagehttps://flyextremeworld.com/pg/essay/44-social-media-impacts-on-the-english-language.html

Divya Singh / ChristophStückelberger (Eds.) (Jan 2017), Ethics in Higher Education, Values-driven Leaders for the Future, Globethics.net Education Ethics No. 1

Divya Singh / ChristophStückelberger (Eds.), Ethics in Higher EducationValues-driven Leaders for the FutureGeneva: Globethics.net, 2017 retrieved fromwww.globethics.net.

Harlow, Trina D., "Journey to Refuge: Understanding Refugees, Exploring Trauma, and Best Practices for Newcomers and Schools" (2019). NPP eBooks. 26. https://newprairiepress.org/ebooks/26/

Hatice Kizgin et al(2018) The Impact of Social Media on Consumers' Acculturation and Purchase Intentions Vol. 20, No. 3 pp 503-514 https://doi.org/10.1007/s10796-017-9817-4

Hatice Kizgin et al(2020) The impact of social media on consumer acculturation: Current challenges, opportunities, and an agenda for research and practice Vol.51.Ward/Bochner/Furnham2001 International Journal of Information Management .Copyright $\quad$ (C) 2021 Elsevier $\quad$ B.V. https://doi.org/10.1016/j.ijinfomgt.2019.10.011

Hermione Foster (2015) How is social media changing the English language? Language Services Direct Retrieved from https:/www.languageservicesdirect.co.uk/social-media-changing-english-language/

IntekoNyarwanda y'Ururimi n'Umuco (2018), Indangagaciro z'umuco w' u Rwanda. Igitabonyobozi (C) B.P. 5796 KIGALI.

Kankan We (2020), A Review of Literature on Social Media and Acculturation Open Journal of Social Sciences, 2020, 8, 19-29 Scientific Research Publishing https://www.scirp.org/journal/jss

Kankan We (2020), A Review of Literature on Social Media and Acculturation Open Journal of Social Sciences, 2020, 8, 19-29 https://www.scirp.org/journal/js

Karissa Johnston et al (2019 Methods of sample size calculation in descriptive retrospective burden of illness studies

Kim, Y.Y. (2001), Becoming Intercultural: An Integrative Theory of Communication and Cross-Cultural Adaptation. Thousand Oaks, CA: Sage.

Krejcie, R.V., \& Morgan, D.W., (1970). Determining Sample Size for Research Activities. Educational and Psychological Measurement.Kraidy, M.M. (2002). Hybridity in cultural globalization. Communication Theory, 3: 316-339

Kyunghee Ma et al (2020) Challenges in Acculturation among International Students from Asian Collectivist Cultures. Higher Education Studies; Vol. 10, No. 3; Published by Canadian Center of Science and Education

Li, C. \& Tsai, W.S. (2015). Social media usage and acculturation: A test with Hispanics in the U.S. Computers in Human Behavior. 45: 204-212.

Mitra, A., \&Evansluong, Q. (2019). Narratives of Integration: Liminality in Migrant Acculturation through Social Media. Technological Forecasting and Social Change, 145, 474-480. https://doi.org/10.1016/j.techfore.2019.01.011

National culture heritage policy February (2015), Ministry of sports and culture, Rwanda.

NCC (2012:) The Situation of Street Children in Rwanda: Prevalence, Causes and Remedial Measures, Kigali.

Park, N., Song, H., \& Lee, K. M. (2014). Social networking sites and other media use, acculturation stress, and psychological well-being among East Asian college students in the United States. Computers in Human Behavior, 36, 138-146.

Qionglei $Y u$ et al (2019) Far apart yet close by: Social media and acculturation among international students in the UK Technological Forecasting and Social Change Vol. 145, 2019, 493-502 https://doi.org/10.1016/j.techfore.2018.09.026Get rights and content

Rwanda (2010), Official Gazette no 13 of 29/03/2010, Ministerial Order Nº01/10 Of 17/03/2010 Establishing The Organisation And Functioning Of Rehabilitation Centers For Minors, article 7\&8)

Sawyer, Rebecca, (2011)."The Impact of New Social Media on Intercultural Adaptation" Senior Honors Projects. Paper 242.

Selmer, J. (1999), Culture shock in China? Adjustment pattern of western expatriate business managers, International Business Review, 8: 515-534.

Selmer, J. (2001), Coping and adjustment of Western expatriate managers in Hong Kong, Scandinavian Journal of Management, 17: 167-185.

Sherly Marliasari ( 2017 ) The Influence of Social Media toward Language and Culture Students of English Education Study Program at Faculty of Teacher Training and Education of Muhammadiyah University Palembang

Whiting, A., \& Williams, D. (2013). Why people use social media: a uses and gratifications approach. Qualitative Market Research: An International Journal, 16(4), 362-369.

Wilkin, H.A., Katz, V.S., \& Ball-Rokeach, S.J. (2009). The role of family interaction in new immigrant Latino's civic engagement. Journal of Communication, 59: 387-406. 
Xinying Xing et al (2020), Acculturation Strategies of Chinese University Students in the United States in Journal of Advances in Education Research, Vol. 5, No. 1, February 2020 https://dx.doi.org/10.22606/jaer.2020.51002

Young, S.L. (2009), Half and half: an (auto) ethnography of hybrid identities in a Korean American motherdaughter relationship. Journal of International and Intercultural Communication, 2: 139-167.

Zaffar (2016) Issues and Challenges in Higher Education System Review of Research International Online Multidisciplinary Journal Vol.5 Research Scholar, Department of Education, Aligarh Muslim University, Aligarh.

Zahirah Zainal, Noor Hanim Rahmati (2020) Social media and its influence on Vocabulary and Language Learning: A case study European Journal of Education studies. AkademiPengajian Bahasa, UniversitiTeknologi MARA (UiTM), Shah Alam, Malaysia. 